\title{
The roles of letter names and letter sounds in connecting print and speech
}

\author{
REBECCA TREIMAN \\ Wayne State University, Detroit, Michigan \\ LIA SOTAK \\ University of Arizona, Tucson, Arizona \\ and \\ MARGO BOWMAN \\ Wayne State University, Detroit, Michigan
}

\begin{abstract}
Three experiments were carried out to examine the cues that are used in learning to read and spell new words. In a reading task (Experiment 1), even preschoolers who could not read simple real words were able to benefit from print-sound relationships that were based on letter names. They found it easier to learn that the made-up word TM was pronounced as "team" (name condition) than that TM was pronounced as "tame" (sound condition) or as "wide" (visual condition). The letter-name strategy persisted among college students (Experiment 2). In a spelling task (Experiment 3), prereaders and novice readers again did better in the name condition than in the sound condition. The ability to use relationships based on letter sounds emerged later than the ability to use relationships based on letter names. However, sound-based relationships were used to a greater extent in spelling than in reading.
\end{abstract}

An alphabetic writing system involves a system of relationships between the letters in printed words and the sounds in spoken words. In English, for example, the letter $b$ is linked to the phoneme /b/. If one sees a $b$ in a printed word, one can be fairly confident that the corresponding spoken word will contain a /b/. Readers and writers who understand the alphabetic principle can remember the pronunciations of a large number of printed words and can decipher new ones. They can produce reasonable, if not always fully correct, spellings. Given the importance of the alphabetic principle for reading and writing, a number of researchers have asked how children acquire it.

It is widely believed that the acquisition of an alphabetic system unfolds in a sequence of stages (e.g., Ehri, 1998; Frith, 1985; Marsh, Friedman, Welch, \& Desberg, 1981). According to such theories, each stage is characterized by a particular strategy. Earlier strategies are replaced by more advanced ones as children progress. The first stage of literacy development is often called prealphabetic or

Some of these data were presented at the 39th Annual Meeting of the Psychonomic Society, Dallas, November 1998. This research was supported by NSF Grants SBR-9408456and SBR-9807736. We thank Neil Mansharamini and Christine Abadir for assistance with the experiments and Brett Kessler and Iris Levin for comments on a draft of the manuscript. We also thank the children and schools for their participation. Correspondence concerning this article should be directed to R. Treiman, Psychology Department, Wayne State University, 71 W. Warren Ave., Detroit, MI 48202 (e-mail: rtreiman@ sun.science.wayne.edu). logographic. Children at this stage are unable to take advantage of systematic relations between letters and sounds. Instead, they notice and remember salient visual attributes of words, such as the "tail" on the word $d o g$. Children link these visual cues to the words' pronunciations or meanings, allowing them to remember a small number of printed words. Ehri postulates a second stage, the partial alphabetic phase, during which children begin to form systematic connections between the letters in printed words and the sounds in spoken words. These early connections involve only some of the letters and some of the sounds. For example, children may link the $d$ of dish to the /d/ in the word's pronunciation but may be unable to relate the remaining letters to phonemes. With experience, the print-to-sound connections become more complete, and children enter what Ehri calls the full alphabetic phase. At this point, all or almost all of the letters in a word's spelling are linked to the phonemes in its pronunciation. A later advance involves the unitization of letter patterns that occur in a number of different words. This leads to the consolidated alphabetic (Ehri, 1998) or orthographic (Frith, 1985) stage.

Support for the existence of a logographic phase comes from a study by Ehri and Wilce (1985). In this study, middle class kindergartners and preschoolers (mean age, 5 years, 7 months) from the United States were taught to read two sets of made-up words. In the phonetic set, the sounds of the letters could be heard in the spoken words. For example, MSK was pronounced as "mask." In the visual condition, the sounds of the letters were not present 
in the spoken words, but the letters' sizes and positions were varied to give each word a unique shape. For example, $\mathrm{F}_{\mathrm{o}}$ was pronounced as "arm." Ehri and Wilce found that children who could not read any simple words learned the visual spellings more easily than the phonetic spellings. This finding supports the idea that children adopt a logographic strategy during their initial attempts to learn to read. In contrast, children who could already read some words learned the phonetic spellings more readily than the visual spellings.

Further support for a logographic phase comes from a study by Seymour and Elder (1986). These investigators studied Scottish children who entered school at an average age of 4 years, 11 months and began instruction in reading at that time. None of the children knew any lettersound correspondences when they entered school, and only a few were familiar with any letter names. The reading instruction that these children received emphasized the formation of a sight vocabulary; there was little explicit mention of letter-sound correspondences. The children were taught to read around 100 words over the course of the school year, and they mastered over 60 of them, on average. The children's reading times and errors suggested that they generally relied on a logographic method. For example, one child misread smaller as "yellow," commenting that the word must be "yellow" because of the presence of the "two sticks." These results, together with those of Ehri and Wilce (1985), suggest that beginners adopt a logographic reading strategy as a default option (see also Byrne, 1992). Children may rely on this procedure for some time, especially if they are not explicitly taught how to associate letters and sounds.

For many words, children must know the phonemes that the letters represent in order to link print and speech in a systematic manner. For example, they must know that $a$ corresponds to the phoneme /æ/ or that $t$ corresponds to the phoneme / $\mathrm{t} /$ to form even a partial alphabetic connection between $a t$ and "at." However, prereaders from the United States do not usually know the sounds of many letters (see, e.g., Worden \& Boettcher, 1990). Children who would form partial or full alphabetic connections also need sufficient phonemic awareness to understand that /æt/ is made up of two separable phonemes, $/ æ /$ and /t/. Many young children, however, lack this understanding (see, e.g., Snow, Burns, \& Griffin, 1998). As a result, young children may have trouble forming links between print and speech that are based on letter sounds. With some kinds of words, however, children could form rudimentary connections between print and speech on the basis of letter names. For example, a child could construct a partial link between eat and "eat" if he or she knows that $e$ has the name /i/ and that the phoneme /i/ is present in the spoken word. Because children in the United States typically learn the names of letters before they learn their sounds (e.g., Worden \& Boettcher, 1990), they may be able to grasp print-speech relationships that are based on letter names before they can use print-speech relationships that are based on letter sounds.
Treiman and Rodriguez (1999) found preliminary evidence for the idea that young children can take advantage of links between print and speech that are based on letter names before they can take advantage of links that are based on letter sounds. They taught children to read sets of words a different set in each of three conditions. In the name condition, children were presented with made-up words such as TM and BT. The children were told that the words were pronounced as "team" and "beet," respectively. The entire name of the word's first letter could be heard in these pronunciations. The sound condition included pairs, such as TM-"tame," in which the letter's typical sound was present in the spoken word but the full name was not. In the visual condition, the letters varied in size and position so that the printed stimuli looked more distinctive. However, the assigned pronunciations did not make sense on the basis of either letter names or letter sounds. For example, $\mathrm{T}^{\mathrm{M}}$ was pronounced as "wide."

Treiman and Rodriguez (1999) tested preschoolers and kindergartners (mean age, 5 years, 0 months) who were unable to read any simple words. As is typical for prereaders of this age in the United States, these children had a reasonably good knowledge of letter names. They averaged 15.5 correct of 26 when shown printed letters and asked to name them. The children were less knowledgeable about letter sounds, averaging 5.5 correct responses when asked to generate the sounds of the letters. On the word-learning task, the prereaders performed significantly better in the name condition than in the sound condition. That is, they derived some benefit from the letter-name cues. The prereaders' performance in the sound condition was not significantly better than their performance in the visual condition, however. This latter result suggests that the prereaders did not take advantage of letter-sound cues.

The findings of Treiman and Rodriguez (1999) suggest that young children do not always adopt a logographic approach when first confronted with print. Although the prereaders could not take advantage of print-speech relationships that were based on letter sounds, they did benefit from relationships that involved letter names. These children could not be described as alphabetic readers, for their performance was no better when alphabetic cues were available (sound condition) than when such cues were not available (visual condition). However, neither could the children be described as purely logographic readers.

Treiman and Rodriguez (1999) also tested novice readers who could read a few simple words. These children were somewhat older than the prereaders (mean age, 5 years, 6 months) and were more knowledgeable about letter names and letter sounds. Like the prereaders, the novice readers performed significantly better in the name condition of the word-learning task (e.g., TM"team") than in the sound condition (e.g., TM-"tame"). Unlike the prereaders, the novice readers showed a significant advantage for the sound condition over the vi- 
sual condition (e.g., TM-“wide"). The results for the novice readers support the idea that children enter the partial alphabetic phase as they learn to read. More knowledgeable about letter sounds, the novice readers could often link at least one of the letters in the printed TM to the phonemes in the spoken "tame." Their performance suffered when such relationships were not available, as when TM was pronounced as "wide." The results further suggest that the letter-name cues favored by beginners are not abandoned when children begin to grasp the alphabetic principle. Novice readers are starting to use letter-sound information, but they continue to use the more primitive letter-name strategy as well.

To further examine the use of the letter-name strategy across the course of reading development, in the present study, we examined a wider range of developmental levels than those investigated by Treiman and Rodriguez (1999). The participants in Experiment 1 were younger and less knowledgeable about letters than were the prereaders tested by Treiman and Rodriguez. Given their low levels of letter-name knowledge, we expected that they would be unable to use a letter-name strategy. The participants in Experiment 2 were college students, substantially more advanced than the novices tested by Treiman and Rodriguez. If letter names continue to play a role throughout the course of reading development, evidence for their use might be found even among college students. Both Experiments 1 and 2 used the word-learning task developed by Treiman and Rodriguez to look at participants' use of various types of cues when learning to pronounce novel words.

A second goal of the present study was to extend the investigation to spelling. As we will discuss in more detail later, several influential theories have proposed that spelling and reading do not develop at the same pace. It is thought that children are able to use the alphabetic principle in spelling before they do so in reading. We tested this idea by developing a spelling version of the word-learning task for use with prereaders and novice readers in Experiment 3.

\section{EXPERIMENT 1 \\ Prereaders With Low Levels of Letter-Name Knowledge in the Reading Version of the Word-Learning Task}

In Experiment 1, we used the reading version of the Treiman and Rodriguez (1999) word-learning task with prereaders who had low levels of letter knowledge. We selected children who could not read any of the simple words used by Treiman and Rodriguez and who produced six or fewer correct responses when shown the letters of the alphabet and asked to name them. De Abreu and Cardoso-Martins (1998) included a group of prereaders with similarly low knowledge of letter names in their study of Brazilian children. These children performed significantly better on words that were visually distinctive (similar to the visual condition of the present study) than on words that contained letter-name cues (similar to the name condition of the present study). We expected to find a similar pattern of results with children in the United States. The prereaders tested by Treiman and Rodriguez may have known enough about letter names that they no longer used a logographic strategy. However, we expected to find such an approach among the children of the present study.

\section{Method}

\section{Stimuli}

The word-learning task was the same as that in Treiman and Rodriguez (1999). There were three sets of two-letter items, with five items in each set. In the name and the sound conditions, the stimuli were printed in uppercase letters of uniform height. In the visual condition, the heights of the letters varied within each printed item. Some letters were offset above the line, and other letters were below it. Table 1 shows the two-letter sequences that were used and the pronunciation that was assigned to each stimulus in each condition.

As was described in Treiman and Rodriguez (1999), the spoken words that were assigned to the printed stimuli were similar in frequency across the three conditions. Imageability is another factor that appears to affect children's ability to learn to read words (e.g., Laing \& Hulme, 1999). We thus asked 15 individuals working with children of the same ages as those in this study and the Treiman and

Table 1

Pairs Used for the Reading and Spelling Versions of the Word-Learning Task

\begin{tabular}{|c|c|c|c|c|}
\hline Set & $\begin{array}{l}\text { Printed } \\
\text { Letters }\end{array}$ & $\begin{array}{c}\text { Name Condition } \\
\text { Pronunciation }\end{array}$ & $\begin{array}{c}\text { Sound Condition } \\
\text { Pronunciation }\end{array}$ & $\begin{array}{c}\text { Visual Condition } \\
\text { Pronunciation } \\
\end{array}$ \\
\hline \multirow[t]{5}{*}{ A } & BT & beet & bait & ham \\
\hline & TR & tear* & tore & fin \\
\hline & PL & peel & pole & robe \\
\hline & CD & seed & sad & wife \\
\hline & KN & cane & cone & goal \\
\hline \multirow[t]{5}{*}{ B } & BD & bead & bud & wine \\
\hline & TS & tease & ties & rich \\
\hline & $\mathrm{JL}$ & jail & jewel & hid \\
\hline & KP & cape & coop & yell \\
\hline & $\mathrm{DR}$ & dear & door & chop \\
\hline \multirow[t]{5}{*}{$\mathrm{C}$} & BN & bean & bone & loaf \\
\hline & $\mathrm{TM}$ & team & tame & wide \\
\hline & DL & deal & dial & hem \\
\hline & KS & case & cuss & mice \\
\hline & PK & peek & pack & shut \\
\hline
\end{tabular}

*As in cry. 
Rodriguez study to rate the words in terms of how easily they would evoke a clear picture in the minds of children in this age range. A scale from 1 (low) to 7 (high) was used. The average imageability rating was 4.61, and there were no significant differences in imageability among the responses in the three conditions.

To assess the children's reading ability, we used the same 22 words as those in Treiman and Rodriguez (1999). Eleven cards were prepared, each containing 2 simple words and one easily identifiable color picture. For the tests of letter-name and letter-sound knowledge, 26 cards were prepared. An uppercase letter was printed on each card.

\section{Procedure}

The first session began with the reading task. If a child read none of the words, the letter-name and letter-sound tasks were then given. Approximately half of the children did the name task first, and the other children did the sound task first. Sessions 2, 3, and 4, which were given only to those children who met the criteria for the study, each included one condition of the word-learning task. The order of the conditions was balanced across children, as was the assignment of stimulus sets to conditions. Children thus learned a different set of stimuli in each condition. The sessions averaged between 3 and 5 days apart.

Reading task. As in Treiman and Rodriguez (1999), the experimenter showed the child one of the cards with two words and a picture and asked the child to identify any items that he or she knew. If the child did not identify all three items, the experimenter pointed to each one in turn and asked the child if he or she recognized it. The order of the cards was randomized for each child.

Letter-name and letter-sound tasks. These tasks were administered and scored as in Treiman and Rodriguez (1999). For the name task, the child was shown the letter cards in a random order and was asked to say the name of each letter. If the response was incorrect, the child was given two alternatives and asked to choose the correct one. The same cards were used for the sound task, but here the child was asked to provide the sound of each letter. If the child did not respond correctly in the free-choice sound task, two alternatives were provided. The letter-name and letter-sound tasks were scored in two ways. By the strict system, children were counted as correct only if they responded correctly in the free-choice situation. By the lenient system, children were scored as correct if they responded correctly on either the free-choice or the two-choice task.

Word-learning task. Each condition of the word-learning task consisted of a demonstration phase followed by up to eight test trials. The procedure was the same as that in Treiman and Rodriguez (1999). The experimenter began the demonstration phase by saying that the child would learn to read some "made-up words." The experimenter showed the child one of the cards. She told the child what the "word" said, running her fingers under its letters. The experimenter used the word in a short sentence and then asked the child to repeat the word. The experimenter again pointed to the printed stimulus and pronounced it twice. This procedure was repeated for all five stimuli, their order randomly chosen for each child.

For the first test trial, the experimenter showed the child one of the cards and asked whether he or she remembered what it said. The experimenter provided the correct answer if the child could not and praised the child if he or she answered correctly. This procedure was repeated for all five stimuli in a randomly chosen order. The procedure for the remaining test trials was the same as that for the first test trial. The criterion for success was two consecutive test trials on which the child responded correctly to all five items. If the child reached this criterion, no further test trials were given in that condition, and the child was given a score of 5 (all items correct) for the remaining trials.

\section{Participants}

We tested children who attended preschools and daycare centers in and around Detroit, Michigan. All were native speakers of English from middle class backgrounds. We screened children between 3 years, 5 months and 4 years, 11 months to find those who could not read any of the words in the reading task and who produced the names of six or fewer letters in the free-choice version of the lettername test. Table 2 provides information about the 30 children who fit our criteria and who completed the experiment. These children were 9 months younger, on average, than the prereaders tested by Treiman and Rodriguez (1999). They were less knowledgeable about letter names and letter sounds. However, they performed significantly above chance on the two-choice letter-name task $[t(29)=$ $4.88, p<.001$, one tailed].

\section{Results}

Figure 1 shows the mean number of correct responses on the word-learning task as a function of condition and trial. The data from this and the following experiments were analyzed using a multivariate approach (O'Brien \& Kaiser, 1985), since preliminary tests showed a lack of sphericity in some cases, especially those involving the trial variable. There were main effects of condition $[F(2,28)=4.94, p=.015]$ and trial $[F(7,23)=6.88, p<$ $.001]$. The interaction between the two variables was not significant $(p=.24)$. Follow-up tests showed that the children performed reliably better in the name condition than in the sound or the visual condition, which were statistically indistinguishable from one another. The superiority for the name condition over the other two conditions was evident for all three sets of stimuli. Only 1 of

Table 2

Information About the Children in Experiments 1 and 3 (Standard Deviations in Parentheses)

\begin{tabular}{|c|c|c|c|}
\hline Measure & $\begin{array}{c}\text { Experiment } 1 \\
\text { Prereaders With Low } \\
\text { Letter-Name Knowledge }\end{array}$ & $\begin{array}{c}\text { Experiment } 3 \\
\text { Prereaders } \\
\end{array}$ & $\begin{array}{c}\text { Experiment } 3 \\
\text { Novice Readers } \\
\end{array}$ \\
\hline Number of prekindergartners & $30(16 \mathrm{~F}, 14 \mathrm{M})$ & $30(16 \mathrm{~F}, 14 \mathrm{M})$ & $7(5 \mathrm{~F}, 2 \mathrm{M})$ \\
\hline Number of kindergartners & 0 & $6(4 \mathrm{~F}, 2 \mathrm{M})$ & $29(10 \mathrm{~F}, 19 \mathrm{M})$ \\
\hline Mean age $(S D)$ in months & $51.3(5.4)$ & $59.6(5.4)$ & $68.2(6.7)$ \\
\hline Mean number $(S D)$ of words read (of 22) & $0.0(0.0)$ & $0.0(0.0)$ & $11.0(7.6)$ \\
\hline Mean number correct $(S D)$ on letter-name test, strict criterion (of 26) & $3.0(2.1)$ & $15.3(8.5)$ & $25.4(1.6)$ \\
\hline Mean number correct $(S D)$ on letter-name test, lenient criterion (of 26) & $15.8(3.1)$ & $22.0(4.0)$ & $26.0(.2)$ \\
\hline Mean number correct $(S D)$ on letter-sound test, strict criterion (of 26) & $0.9(1.3)$ & $4.4(4.8)$ & $20.4(4.6)$ \\
\hline Mean number correct $(S D)$ on letter-sound test, lenient criterion (of 26) & $13.8(2.5)$ & $17.1(4.1)$ & $24.9(1.6)$ \\
\hline
\end{tabular}




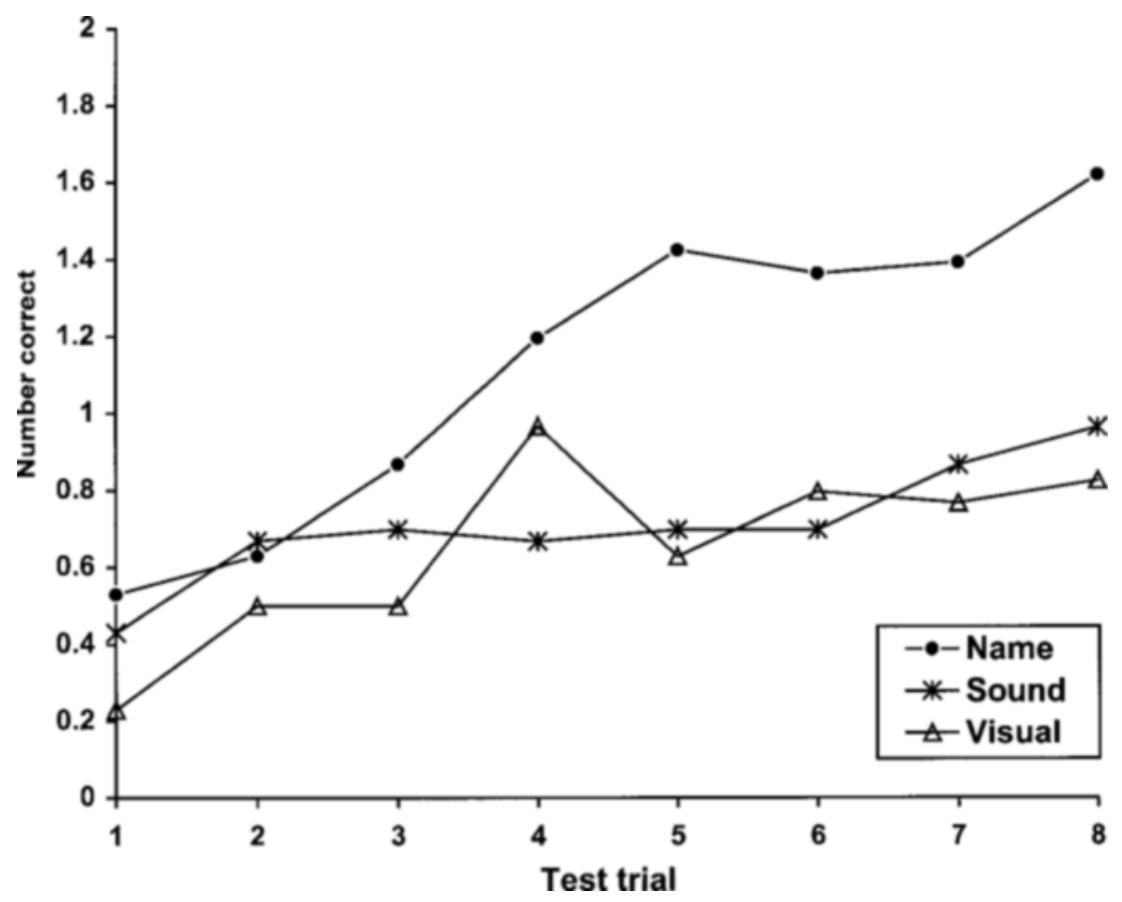

Figure 1. Mean number of correct responses (out of five possible) as a function of trial for prereaders with low levels of letter knowledge in the reading task of Experiment 1.

the 30 children reached the criterion in the name condition, and no child reached the criterion in the sound or the visual condition.

The most common type of error in the word-learning task was a failure to provide a response. No-response errors constituted $59 \%$ of the errors, pooling across the three conditions. Next most common were responses that were correct for another item in the same set. These list errors constituted $26 \%$ of all errors. Phonological errors were defined, as in Treiman and Rodriguez (1999), as responses that were not in the current list (or the list learned in the immediately preceding session) and for which at least one phoneme in the response corresponded to a letter in the same position of the stimulus. These made up just $2 \%$ of the errors. The remaining $13 \%$ of the errors, such as "Batman" for DR, did not fall into any of the preceding categories. There were no significant differences among the three conditions in the types of errors made.

\section{Discussion}

The prereaders in this study were younger and less knowledgeable about letters than were the prereaders tested by Treiman and Rodriguez (1999). Their overall level of performance on the word-learning task was also lower. Despite these differences, the present prereaders showed the same pattern of performance as those tested by Treiman and Rodriguez. The children found it easier to learn the links between the printed stimuli and the spo- ken responses in the name condition than in the sound or the visual condition. The prereaders in this study, like those tested by Treiman and Rodriguez, could benefit to some degree from the letter-name cues in pairs such as TM for "team." However, they could not use the lettersound cues in pairs such as TM-"tame." They performed no better on such pairs than on arbitrary pairs, such as TM-"wide."

The results do not support our initial hypothesis that prereaders with low levels of letter-name knowledge are logographic learners. With the number of learning trials allotted here, the children did not perform best in the visual condition. Instead, they derived some benefit from print-speech relationships that were based on letter names. The prereaders' receptive knowledge of letter names, as shown by their above-chance performance on our twochoice letter-name recognition task, may have allowed them to pick up the relationship between a letter string such as TM and a spoken syllable such as "team." Ehri and Wilce (1985) also postulated that the ability to recognize associations is sufficient to allow children to process them and retain them in memory. An ability to generate the associations is not necessarily required.

Our results differ from those of De Abreu and CardosoMartins (1998), who found that Brazilian prereaders who could produce the names of six or fewer letters did not show an advantage for spellings that included lettername clues over spellings that did not. It is possible that the Brazilian children lacked the ability to recognize letter 
names, as well as the ability to produce them; this cannot be assessed, because no letter-name recognition task was included in the study. Also, although the entire name of the word's first letter could be heard in most of the pronunciations used by De Abreu and Cardoso-Martins, this was not true for one of their stimuli. The words used in the Brazilian study varied greatly in their phonological structure, with most of the spellings containing more than two letters. In our letter-name condition, the complete name of the first letter could be heard in the pronunciations of all the items, and there was only one other letter in each item. For these reasons, the letter-name cues may have been more salient in the name condition of our study than in the corresponding condition of De Abreu and Cardoso-Martins's study.

Our results suggest that even prereaders with a modest amount of letter-name knowledge begin to use this knowledge in making connections between print and speech. These children can be described as prealphabetic, for they are not yet able to use relationships that are based on letter sounds in linking print and speech. However, the children do not rely solely on rote memorization either. In this sense, they are not limited to a logographic strategy.

\section{EXPERIMENT 2 \\ Adults in the Reading Version of the Word-Learning Task}

In Experiment 2, we modified the word-learning task so that it would be suitable for adults. On one view, letter names provide a way of gaining entry into the alphabetic system. Once learners have grasped the alphabetic principle, however, they use the sounds of the letters to link print and speech, and they no longer consider the letters' names. On this view, skilled readers of English should learn TM as a spelling of "team" no more easily than TM as a spelling of "tame." What matters is that $t$ corresponds to the phoneme $/ \mathrm{t} /$, not that $t$ has the conventional label /ti/. This outcome would be consistent with stage theories of literacy development, in which the strategies that characterize earlier stages are replaced by those of later stages as children progress. An alternative hypothesis is that even skilled readers use print-speech relationships based on letter names when such relationships are available. Such an outcome would support the idea that, in literacy development as in other aspects of cognitive development, the introduction of more advanced strategies does not necessarily mean the abandonment of earlier strategies (e.g., Rittle-Johnson \& Siegler, 1999). On this view, the name condition should yield better performance than does the sound condition, even among adults. Both views predict that adults will perform poorly in the visual condition, which offers neither letter-name nor letter-sound cues.

\section{Method}

Stimuli

The stimuli for the word-learning task were the same as those in Experiment 1.

\section{Procedure}

The procedure for the word-learning task was similar to that used with children. However, the adults received all three sets of stimuli15 in all-in each condition. The maximum number of trials per condition was 10 , rather than 8 , as for the children. The adults participated in all three conditions in a single session, with a 5-min

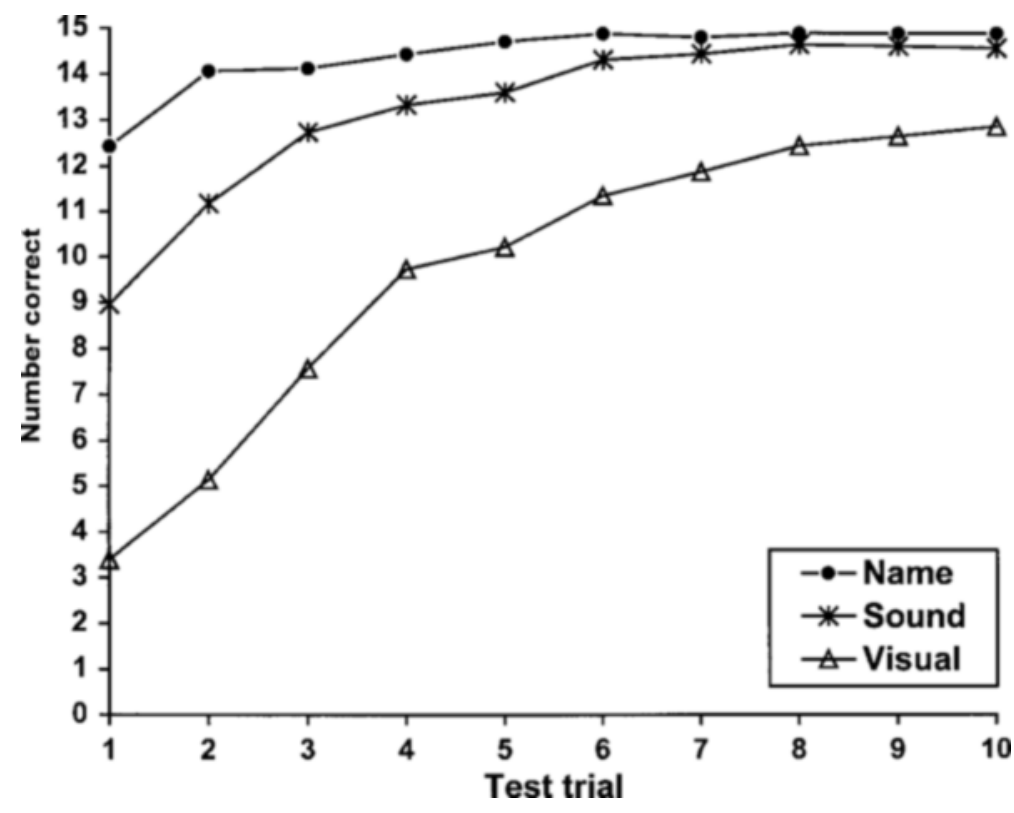

Figure 2. Mean number of correct responses (out of 15 possible) as a function of trial for adults in the reading task of Experiment 2. 
break between conditions. The order of conditions was balanced across participants, with either 4 or 5 participants being assigned to each of the six possible orders.

\section{Participants}

Twenty-eight college students (or, in one case, a recent graduate) participated in exchange for extra credit or on a voluntary basis. All were native speakers of English.

\section{Results}

Figure 2 shows the mean number of correct responses as a function of condition and trial. There was a main effect of condition $[F(2,25)=38.14, p<.001]$, a main effect of trial $[F(9,19)=30.84, p<.001]$, and an interaction between the two variables $[F(18,10)=7.13, p=.002]$. Given the interaction, separate analyses were carried out for each trial. On Trials 1-6, the participants performed best in the name condition, significantly more poorly in the sound condition, and significantly more poorly again in the visual condition. On Trials 7-10, the difference between the name and the sound conditions was no longer reliable, owing to ceiling effects. However, performance in the visual condition continued to be significantly worse than performance in the name and the sound conditions. All three sets of stimuli showed the same pattern of best performance in the name condition, intermediate performance in the sound condition, and poorest performance in the visual condition. Of the 28 participants, 27 reached criterion in the name condition, 26 did so in the sound condition, and only 12 did so in the visual condition.

Table 3 shows the mean proportions of errors of various types in each of the three conditions, using the same criteria to classify errors as those in Experiment 1 . The means and statistical analyses are based on those 18 participants who made at least one error in each condition. Errors in which the participant did not provide a response were the most common type and did not vary significantly across the three conditions. List errors were significantly more common in the visual condition than in the other conditions $(p<.001)$. This difference suggests that the participants attempted to memorize the responses in the visual condition, causing them to confuse items within the set. Phonological errors were more common in the name and the sound conditions, which did not differ significantly from one another, than in the visual condition $(p<.001)$. Errors that did not fit into any of the preceding categories were equally frequent across the three conditions.

Table 3

Mean Proportions of Errors of Various Types in the Reading Task of Experiment 2

\begin{tabular}{lccc}
\hline & \multicolumn{3}{c}{ Condition } \\
\cline { 2 - 4 } Error Type & Name & Sound & Visual \\
\hline No response & .60 & .65 & .52 \\
List & .02 & .02 & .41 \\
Phonological & .35 & .25 & .01 \\
Other & .03 & .09 & .06 \\
\hline
\end{tabular}

\section{Discussion}

The results of Experiment 2 indicate that adults, like young children, readily use the names of letters to link print and speech. The adults tested here, like the children tested in Experiment 1 and in Treiman and Rodriguez (1999), found it more natural that TM should be pronounced as "team" than that TM should be pronounced as "tame." The use of letter names to connect print and speech-a strategy that emerges even before children are able to read any words-is still observed among fluent readers. This finding is consistent with reports that adults are influenced by the names of letters in such tasks as phoneme counting (Treiman \& Cassar, 1997). Although letters' names are not always good guides to their pronunciations within words, adults continue to use this information in reading and related tasks.

The adults in Experiment 2 had difficulty with the arbitrary pairs in the visual condition, performing substantially worse in this condition than in the sound condition. In this respect, the adults differed from the prereaders tested in Experiment 1 and in Treiman and Rodriguez (1999), who did not show a significant difference between the sound condition and the visual condition. The superiority for the sound condition over the visual condition found here is consistent with results reported by Baron (1977) and Brooks (1977). In those studies, adults were given extensive practice in reading a set of six novel words. Their times to read the list approached a lower asymptote when the words' pronunciations were related to their spellings in a systematic manner than when the words' pronunciations were arbitrary. To our knowledge, no previous study with adults has included a condition that is similar to the name condition of the present study.

The adults' pattern of performance in Experiment 2best in the name condition, significantly poorer in the sound condition, and significantly poorer again in the visual condition-is the same pattern as that observed for novice readers in Treiman and Rodriguez (1999). The results thus suggest that readers, whether beginning or advanced, use letter sounds to link print and speech. There is an additional boost from letter names, an effect that emerges before children can read any words and that continues into adulthood.

\section{EXPERIMENT 3 Prereaders and Novice Readers in the Spelling Version of the Word-Learning Task}

In the experiments reported so far, participants were shown a printed stimulus and asked to pronounce it. This task was designed to model the processes involved in learning the pronunciations of new words. In Experiment 3, we sought to develop a model of the processes involved in learning to spell. The extension of our research to spelling was motivated by the question of whether spelling and reading show similar patterns of development. Several influential theorists have proposed that learning to spell and learning to read do not always 
proceed at the same pace. Frith (1985) has argued, in fact, that the two are frequently out of step. In her view, the transition from the logographic phase to the alphabetic phase takes place earlier for spelling than for reading. As a result, children use the alphabetic principle in spelling before they do so in reading. A similar view has been put forward by Goswami and Bryant (1990), and supporting evidence comes from studies by Bradley and Bryant (1979) and Huxford, Terrell, and Bradley (1991). If spelling develops more rapidly than reading, even prereaders might show a difficulty with the visual condition, relative to the sound condition, when learning to spell.

Also of interest was whether children would show a superiority for the name condition over the sound condition in spelling, as they do in reading. A number of previous studies have found that children use their knowledge of letter names when spelling words (e.g., Read, 1975; Treiman, 1993, 1994; Treiman, Tincoff, \& RichmondWelty, 1996). For example, children may spell car as KR or eat as ET, using a letter to represent the entire sound of its name. Given these results, we expected to find a superiority for the name condition over the sound condition in the spelling task.

The spelling version of the word-learning task used the same pairs of printed and spoken stimuli as the reading version of Experiments 1 and 2. This time, however, the spoken words were pronounced for the children, and the children were asked to construct their spellings.

\section{Method}

\section{Stimuli}

Plastic and foam rubber letters were used in place of the printed stimuli of the earlier experiments. The letters in the name and the sound conditions were uniform in size, color, and material. They consisted of yellow, foam rubber, uppercase block letters, $5.1 \mathrm{~cm}$ in height. For the visual condition, each two-letter spelling was made up of two uppercase letters that differed in size, color, and material. The larger member of the pair was a 5.1-cm-high foam rubber letter in block style that was either yellow or blue. The smaller one was a block style plastic letter $3 \mathrm{~cm}$ high in green, blue, red, yellow, orange, or pink. Each word in a set contained a different colored small letter. The large letter occurred in the first position in some words and in the last position in other words.

The letters needed to spell the words were displayed on a green and blue $38-\mathrm{cm}$-wide $\times 32-\mathrm{cm}$-high felt board. The board was placed horizontally in front of the child so that the green side was above the blue side. Letters were laid out randomly on the green portion of the board. A 16.8 -cm-wide $\times 13$-cm-high spelling board was centered on the bottom blue portion of the felt board. The spelling board was made of plastic canvas covered in green felt. A $3.5-\mathrm{cm}$-wide frame of either red or blue felt surrounded the entire spelling board, leaving a 9.8 -cm-wide $\times 6$-cm-high opening of green felt in the center of the board. A yellow vertical line placed in the center of the opening divided the inner area into two side-byside 4.9-cm-wide $\times 6-\mathrm{cm}$-high areas, into which letters were placed to spell the words. A small yellow arrow in the upper left corner of the spelling board reminded the child where to place the first letter. Puppets were used to demonstrate the spelling of the words. A different puppet was used for each condition.

\section{Procedure}

Session 1 was devoted to the letter-name, letter-sound, and reading tasks. The stimuli, procedures, and scoring methods for these tasks were the same as those in Experiment 1. Sessions 2, 3, and 4 were each devoted to a different word-learning condition, with a different set of stimuli used for each condition. The orders of the conditions, sets, and puppets were counterbalanced across the children in each reading group. The sessions averaged between 5 and 6 days apart.

Each of the word-learning sessions began with the experimenter introducing the selected puppet and telling the child that he or she was going to learn to spell words the way the puppet spelled them. It was stressed that the puppet did not spell the words the same way that people do. The child was told that the puppet always used one of the special spelling boards, and the child was allowed to choose either the red or the blue board. The experimenter explained that the puppet always used two letters to spell each word. To demonstrate the placement of the letters, the puppet pretended to choose one letter and put it in the left opening on the spelling board. It was explained that the yellow arrow was a reminder of where to place the first letter. The puppet then directed the child's attention to the remaining opening as the space where the second letter was to be placed.

During the demonstration trial, the five words were presented one at a time in a random order. For each word, the puppet picked up the first letter and put it into the left opening on the spelling board, pointing out that the letter was in the correct place because the yellow arrow pointed toward it. Next, the puppet picked up the second letter and placed it in the second space. The puppet then pointed to the two letters, told the child the word that the letters spelled, used the word in a sentence, and repeated the word again. The puppet asked the child to say the word and corrected the child's pronunciation, if necessary. The child's attention was directed to the word one final time while the puppet pronounced it again. The letters were then removed from the spelling board.

For each test trial, the words were presented in a random order. The experimenter said each word and asked the child to spell it the way the puppet did. If necessary, the child was guided as to where to place the letters. If the child was reluctant to choose the proper number of letters, he or she was encouraged to "just try" to spell the word like the puppet did. Once the child had selected and placed two letters, feedback was given. The child was praised if he or she responded correctly. When a response was incorrect, the child was told that he or she did a good job choosing letters but that the letters were not exactly the same ones that the puppet used to spell the word. In such cases, the puppet removed the incorrect letters and replaced them with the correct ones so that the child could see the puppet's spelling. The letters were removed before the next word was given.

The maximum number of test trials per condition was eight, as in Experiment 1. Testing in a condition was discontinued if a child reached a criterion of two consecutive trials on which all five words were correct. After the final session, the children were shown the conventional spellings of all the words.

\section{Participants}

Children were tested in daycare centers, preschools, and kindergartens serving middle class populations in the Detroit area. We selected 36 children who could read no words on our reading task and 36 children who could read at least one word. As Table 2 shows, the majority of the prereaders had not yet begun kindergarten. The majority of the novice readers were kindergartners. All of the children were native speakers of English. Three additional children began the study but chose not to continue. Another child moved away from the area and could not finish the study.

\section{Results}

Figure 3 shows the mean number of correct responses on each trial as a function of condition (name vs. sound vs. visual) and reading group (prereader vs. novice reader). 


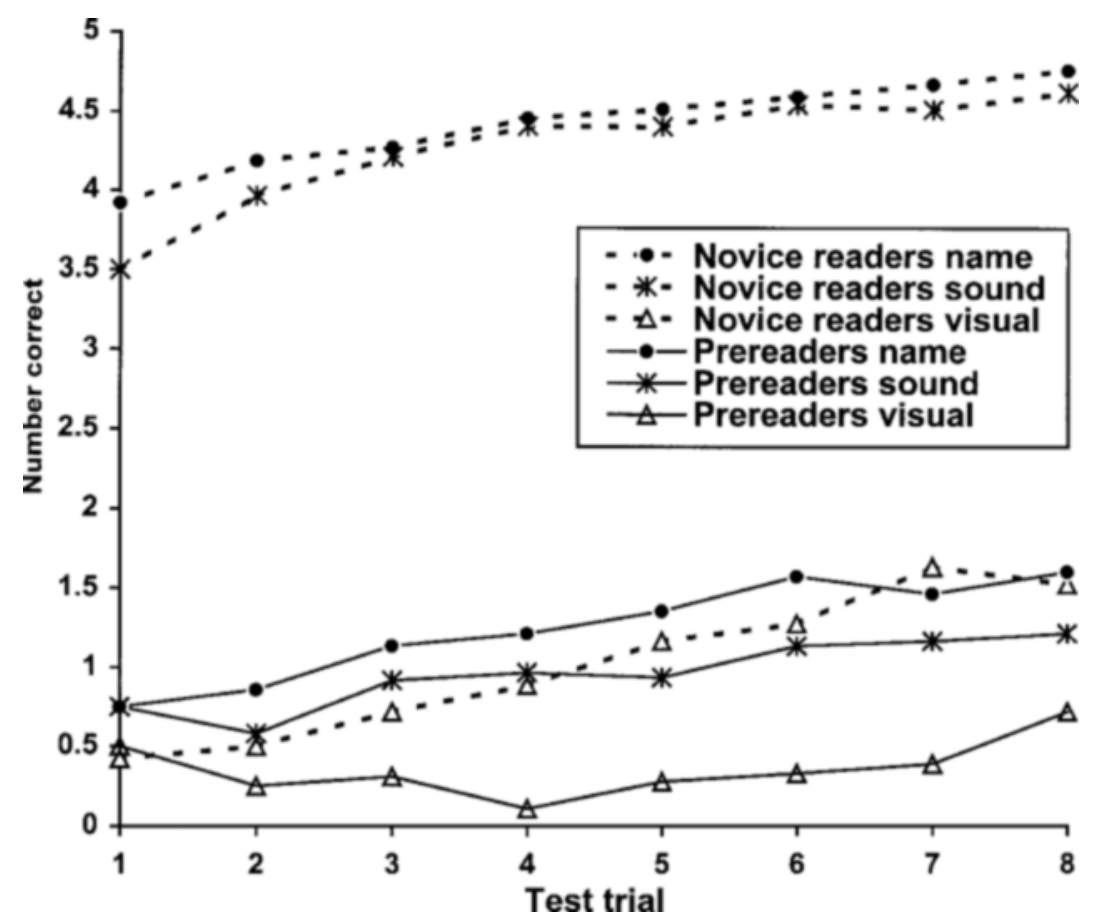

Figure 3. Mean number of correct responses (out of five possible) as a function of trial for prereaders and novice readers in the spelling task of Experiment 2.

Analyses using the factors of condition, trial, and reading group showed a main effect of condition $[F(2,69)=$ $106.02, p<.001]$, which interacted with reading group $[F(2,69)=42.49, p<.001]$. There was also a main effect of trial $[F(7,64)=13.99, p<.001]$ and an interaction between trial and reading group $[F(7,64)=2.42, p=.029]$. A main effect of reading group was also found $[F(1,70)$ $=143.65, p<.001]$, with novice readers outperforming prereaders.

Given the interactions involving reading group, we analyzed the results for each group separately. Main effects of condition were found for both prereaders $[F(2,34)=$ $7.21, p=.002]$ and novice readers $[F(2,34)=167.27, p<$ $.001]$. The interaction between condition and reading group in the main analysis reflected the fact that the two groups showed somewhat different patterns of performance. The prereaders performed best in the name condition, intermediate in the sound condition, and most poorly in the visual condition. All of the between-conditions differences were significant. This pattern-best perfor- mance in the name condition, intermediate performance in the sound condition, and poorest performance in the visual condition - was found for all three sets of stimuli. For the novice readers, the difference between the name and the sound conditions was not reliable. There was a trend in this direction, however, and the name condition yielded better performance than did the sound condition for all three sets of stimuli. The visual condition was significantly more difficult than the other two conditions for the novice readers. This effect was seen for all three sets of stimuli.

We found main effects of trial for both prereaders $[F(7,29)=4.79, p=.001]$ and novice readers $[F(7,29)=$ $14.82, p<.001]$. The interaction between trial and reading group occurred because the novice readers improved more rapidly across trials than did the prereaders. For neither the prereaders nor the novice readers was there a significant interaction between condition and trial.

The percentage of prereaders reaching criterion was $14 \%$ in the name condition, $8 \%$ in the sound condition,

Table 4

Mean Proportions of Errors of Various Types in the Spelling Task of Experiment 3

\begin{tabular}{lccccccc}
\hline & \multicolumn{3}{c}{ Prereaders } & & \multicolumn{3}{c}{ Novice Readers } \\
\cline { 2 - 4 } \cline { 6 - 8 } \multicolumn{1}{c}{ Error Type } & Name & Sound & Visual & & Name & Sound & Visual \\
\hline List error & .09 & .09 & .12 & & .17 & .08 & .11 \\
First letter correct & .33 & .21 & .13 & & .65 & .55 & .19 \\
Second letter correct & .08 & .15 & .10 & & .03 & .18 & .12 \\
Other errors & .50 & .55 & .65 & & .15 & .20 & .59 \\
\hline
\end{tabular}


and $0 \%$ in the visual condition. The figures for the novice readers were $83 \%, 81 \%$, and $6 \%$, respectively.

Errors in which the children did not provide a response, which were common in the reading task, never occurred in the spelling task. List errors were those in which a child produced the spelling that was correct for another item in the same list. Phonological errors were divided into two categories: those in which the first letter of the spelling was correct and in the correct position and those in which the second letter of the spelling was correct and in the correct position. All remaining errors were placed in the other category. Table 4 shows the proportions of errors in each category for prereaders and novice readers. The results shown in Table 4 and the associated analyses are based on children who made at least one error in each condition.

List errors made up $11 \%$ of all the errors, substantially less than in the reading version of the word-learning task (Treiman \& Rodriguez, 1999; Experiments 1 and 2). An analysis of list errors, using the factors of condition and reading group, found no significant effects. Phonological errors were more common than in previous experiments using the reading version of the word-learning task with children. Errors in which only the first letter was correct, as in ТВ for team, were influenced by condition $[F(2,47)=28.24, p<.001]$, reading group $[F(1,48)=$ $20.37, p<.001]$, and their interaction $[F(2,47)=9.98, p<$ $.001]$. Novice readers were more likely than prereaders to make first-letter-correct errors in the name and the sound conditions. Also, these errors were significantly more frequent in the name condition than in the sound condition. For example, errors that used an initial $t$ were more common for team (name condition) than for tame (sound condition). These errors were relatively uncommon in the visual condition, and there was no significant difference between the reading groups for this condition.

Errors in which the second letter was correct were influenced by condition $[F(2,47)=9.79, p<.001]$ and the interaction between condition and reading group $[F(2,47)=$ $3.20, p=.05]$. Importantly, second-letter-correct errors were more common in the sound condition than in the name condition. For example, errors that retained the $m$ were more likely for tame (sound condition) than for team (name condition). The visual condition showed intermediate results, and the interaction between condition and reading group arose because the visual condition was more similar to the name condition for prereaders and more similar to the sound condition for novice readers.

For prereaders, the only one of the conditions in which first-letter-correct errors reliably outnumbered secondletter-correct errors was the name condition, the condition in which the entire name of the first letter was heard in the spoken word. When learning that team is spelled as TM, prereaders were significantly more likely to produce errors that retained the $t$ than errors that retained the $m$. For novice readers, first-letter-correct errors significantly outnumbered second-letter-correct errors for both the name and the sound conditions, although the difference tended to be larger in the name condition.
A final error analysis focused on other errors. These errors, which appeared to be primarily random guesses, were affected by condition $[F(2,47)=45.59, p<.001]$ and reading group $[F(1,48)=29.70, p<.001]$, as well as by their interaction $[F(2,47)=13.44, p<.001]$. Prereaders made more other errors than did novice readers in the name and the sound conditions. However, the two groups were statistically indistinguishable in the visual condition. For both groups, other errors were significantly more common in the visual condition, where there were no principled relationships between the spoken words and their spellings, than in the two conditions that offered such relationships. This difference was larger for the novice readers.

Our last analyses compared children's performance in the spelling and the reading versions of the word-learning task. For this purpose, we compared the prereaders and novice readers of the present experiment with the prereaders and novice readers tested by Treiman and Rodriguez (1999). The prereaders tested here were very similar in age and letter knowledge to the prereaders of Treiman and Rodriguez, and so it was reasonable to compare the two groups. The novice readers in the present spelling study were significantly better on the reading task and the strict scoring of the letter-sound task than were the novice readers in the reading study of Treiman and Rodriguez. We therefore selected 20 novice readers from each study, so that the mean number of words read was the same for the two groups. The groups thus selected were statistically indistinguishable on the tests of letter knowledge as well.

Figure 4 shows, for these matched groups, the mean number of correct responses pooled across trials on the spelling and the reading versions of the word-learning task. The data were analyzed using the factors of task (spelling vs. reading), reading group (prereader vs. novice), and condition (name, sound, visual). There was an interaction of task, reading group, and condition $[F(2,107)=$ $8.13, p=.001]$, as well as main effects of task $[F(1,108)=$ $30.31, p<.001]$, reading group $[F(1,108)=137.28, p<$ $.001]$, and condition $[F(2,107)=86.05, p<.001]$ and interactions between task and condition $[F(2,107)=19.74$, $p<.001]$ and reading group and condition $[F(2,107)=$ $31.35, p<.001]$. To shed light on the critical three-way interaction, we carried out a follow-up analysis that included only the name and the sound conditions. This analysis revealed that performance was significantly better in the name condition than in the sound condition. The effect did not interact with task or reading group. This result shows that the children benefited from letter names regardless of whether their task involved reading or spelling and regardless of their level of reading skill. In contrast, a follow-up analysis that included the sound and the visual conditions revealed that the difference between these two conditions was affected by task, by reading skill, and by their interaction. Novice readers did significantly better in the sound condition than in the visual condition in both the spelling task and the reading task. However, the visual condition was at a larger disadvan- 


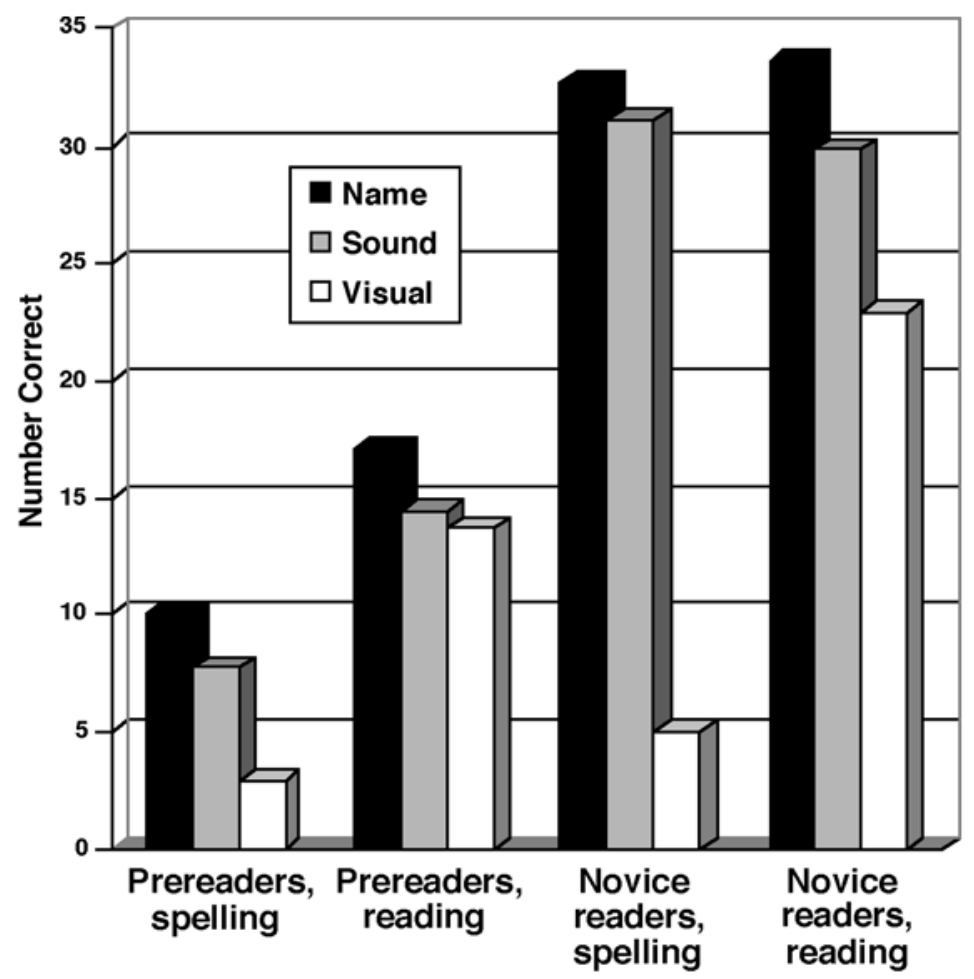

Figure 4. Mean number of correct responses (out of 40 possible) in the spelling and the reading versions of the word-learning task for prereaders and novice readers.

tage in spelling than in reading, as Figure 4 shows. For prereaders, the difference between the sound condition and the visual condition was reliable only in the case of spelling. No significant difference between the sound and the visual conditions was found for reading.

\section{Discussion}

The results of Experiment 3 show that children use letter names when they are learning to link spoken words to printed words, as well as when they are working in the reverse direction. For prereaders, we found a superiority for the name condition over the sound condition in both numbers of correct responses and types of errors made. The prereaders were more likely to produce the correct response when they were taught that "team" was spelled as TM than when they were taught that "tame" was spelled as TM. When they could not provide the correct spelling for a letter-name item, such as TM for "team," they sometimes produced at least the $t$. These first-letter errors appear to predominate because the name of the first letter is heard in the spoken word. No superiority for the first letter over the second letter was observed in the visual condition, where the letters are not meaningfully related to the sounds (for similar results, see De Abreu \& Cardoso-Martins, 1998; Ehri \& Wilce, 1985). The novice readers, like the prereaders, also benefited from the presence of letter names. They performed close to ceiling in both conditions, showing a nonsignificant trend toward better performance in the name condition than in the sound condition. However, the errors of the novice readers testified to their use of letter names.

Just as the prereaders and novice readers used letter names in connecting the spoken words to the printed words, they also used letter sounds. Both groups performed significantly better when the words' spellings made sense on the basis of letter sounds (e.g., "tame" spelled as TM) than when the spellings did not make sense on the basis of letter sounds (e.g., "wide" spelled as TM). The children's difficulty with the visual condition was apparent when their numbers of correct responses and also their errors were examined. Importantly, the visual condition was difficult for prereaders, as well as for novice readers.

The results of the spelling task are similar to those previously observed for reading in that the prereaders and the novice readers benefited from letter names in both tasks. Indeed, a combined analysis of spelling and reading data showed that the superiority for the name condition over the sound condition did not vary significantly across task (reading vs. spelling) and reading level (prereader vs. novice reader). This result suggests that children take advantage of letter names in both spelling and reading. They do so even before they can consistently read any real words.

Differences between spelling and reading emerged when we focused on the sound and the visual conditions. 
Table 5

Correlations Between Children's Performance in Various Conditions of the Word-Learning Task

\begin{tabular}{llcc}
\hline Condition & Name & Sound & Visual \\
\hline & Reading Task $(n=104)$ & \\
Name & - & $.82^{*}$ & $.74^{*}$ \\
Sound & $.74^{*}$ & - & $.72^{*}$ \\
Visual & $.43^{*}$ & $.36^{*}$ & - \\
& & & \\
& Spelling Task $(n=72)$ & \\
Name & - & $.94^{*}$ & $.45^{*}$ \\
Sound & $.81^{*}$ & - & $.47^{*}$ \\
Visual & .17 & .19 & - \\
\hline
\end{tabular}

Note-Results based on total scores are shown above the diagonal, and results based on criterion performance are shown below the diagonal. $* p<.001$, one tailed.

Specifically, the superiority for the sound condition over the visual condition was greater for spelling than it was for reading. In the reading version of the word-learning task, prereaders do not appear to take advantage of lettersound relationships. In two separate studies, no significant superiority for the sound condition over the visual condition was found for prereaders (Treiman \& Rodriguez, 1999; Experiment 1). In the present experiment, however, prereaders did show a reliable difference between the sound and the visual conditions in a spelling task. The comparisons between the spelling and the reading tasks must be interpreted with caution, since the tasks were administered in different experiments to different children. However, the finding that prereaders can benefit from letter-sound relationships in spelling, but not in reading, fits with the claim that the alphabetic principle is used earlier in spelling than in reading (Frith, 1985; Goswami $\&$ Bryant, 1990). Further support for the idea that the alphabetic principle is more important in spelling than in reading comes from our finding that, although beginning readers derived some benefit from letter-sound relationships in both tasks, the lack of such relationships hurt their performance in spelling more than it did in reading. The difference between the spelling and the reading tasks is noteworthy given that the visual condition of the spelling task, unlike that of the reading task, used color to differentiate the stimuli. Despite the salience of color, the children found the visual condition more difficult in spelling than in reading.

\section{CORRELATIONAL ANALYSES}

We have assumed that children's performance in the name and the sound conditions of the word-learning task reflects their ability to benefit from principled relationships between print and speech in learning to read and spell. The visual condition, in contrast, would seem to assess paired-associate learning ability, which is less important in mastering an alphabetic writing system. If these assumptions are correct, we should find a closer relationship between children's performances in the name and the sound conditions than between their performances in either of these conditions and the visual condition. Table 5 presents the relevant correlations. The correlations for reading in this and the following analyses are based on the combined group of children in the present Experiment 1 and children tested by Treiman and Rodriguez (1999). For spelling, the correlations are based on the children from Experiment 3 . Whether performance was assessed by total scores or by attainment of the criterion, the correlation between the name and the sound conditions was always significantly higher $(p<$ .05 , one tailed) than the other two correlations, which were statistically indistinguishable from one another.

If learning to read outside the laboratory draws on the ability to use principled relationships between spellings and sounds - the same ability that is assessed in the name and the sound conditions of our word-learning task-then word reading ability should correlate more highly with performance in the name and the sound conditions than with performance in the visual condition. As Table 6 shows, the correlations between reading ability and performance in the visual condition were numerically lower than the correlations between reading ability and performance in the name and the sound conditions. In most cases, the differences between the correlation coefficients were reliable. Similarly, Ehri and Wilce (1985) reported a higher correlation between reader group and performance in their phonetic condition (similar to the sound condition of the present study) than between reader group and performance in their visual condition.

Additional analyses were carried out to determine how children's knowledge of letter names and letter sounds related to their performance in the three conditions. As Table 7 shows, alphabetic knowledge was generally more closely related to performance in the name

Table 6

Correlations Between Children's Performance in the Various Conditions of the Reading and the Spelling Tasks and Number of Real Words Read

\begin{tabular}{|c|c|c|c|c|}
\hline Condition & $\begin{array}{c}\text { Reading Task, } \\
\text { Total Scores }\end{array}$ & $\begin{array}{c}\text { Reading Task, } \\
\text { Criterion Performance }\end{array}$ & $\begin{array}{c}\text { Spelling Task, } \\
\text { Total Scores }\end{array}$ & $\begin{array}{c}\text { Spelling Task, } \\
\text { Criterion Performance }\end{array}$ \\
\hline Name & $.52 \%$ & $.48_{\mathrm{a}} \neq$ & $67+$ & .58 专 \\
\hline Sound & $.51 \mathrm{a}$ & $.41_{\mathrm{a}}$ & $.70 \mathrm{a}$ & $.67 \mathrm{a}$ \\
\hline Visual & $.37 \mathrm{~b} \neq$ & $.29 \mathrm{~b}^{\dagger}$ & $63_{\mathrm{a}}$ \% & $.28_{\mathrm{b}} *$ \\
\hline
\end{tabular}

Note-Correlation coefficients in the same column that have different subscripts differ at $p<$

.05 , one tailed. $* p<.01$, one tailed. ${ }^{\dagger} p<.005$, one tailed. ${ }^{\ddagger} p<.001$, one tailed. 
Table 7

Correlations Between Children's Performance in Various Conditions of the Reading and Spelling Tasks (Total Scores) and Knowledge of Letter Names and Letter Sounds (Strict Criterion)

\begin{tabular}{lcccccc}
\hline & \multicolumn{2}{c}{ Reading Task $(n=104)$} & & \multicolumn{2}{c}{ Spelling Task $(n=72)$} \\
\cline { 2 - 3 } \cline { 6 - 7 } Condition & $\begin{array}{c}\text { Letter-Name } \\
\text { Knowledge }\end{array}$ & $\begin{array}{c}\text { Letter-Sound } \\
\text { Knowledge }\end{array}$ & & $\begin{array}{c}\text { Letter-Name } \\
\text { Knowledge }\end{array}$ & $\begin{array}{c}\text { Letter-Sound } \\
\text { Knowledge }\end{array}$ \\
\hline Name & $.73 \dagger$ & $.75_{\mathrm{a}}^{\dagger}$ & & $.70_{\mathrm{a}} \dagger$ & $.85_{\mathrm{a}}^{\dagger} \dagger$ \\
Sound & $.76_{\mathrm{a}}^{\dagger}$ & $.78_{\mathrm{a}}^{\dagger}$ & & $.61_{\mathrm{b}}^{\dagger}$ & $.84_{\mathrm{a}}^{\dagger}$ \\
Visual & $.67_{\mathrm{b}}^{\dagger}$ & $.62_{\mathrm{b}}^{\dagger}$ & & $.30_{\mathrm{c}}{ }^{*}$ & $.51_{\mathrm{b}}^{\dagger}$ \\
\hline
\end{tabular}

Note-Correlation coefficients in the same column that have different subscripts differ at $p<.05$, one tailed. $* p<.01$, one tailed. $\quad t p<.001$, one tailed.

and the sound conditions of the word-learning task than to performance in the visual condition.

\section{GENERAL DISCUSSION}

It is widely believed that young children approach learning to read as a rote, paired-associate learning task (e.g., Byrne, 1992; Frith, 1985; Gough \& Hillinger, 1980; Marsh et al., 1981). When it is said that young children are in the logographic stage of reading development (Frith, 1985; Seymour \& Elder, 1986), the implication is that they do not expect systematic relationships between printed and spoken words. Our results suggest, to the contrary, that young children can benefit from at least some kinds of principled relationships between printed and spoken words-those that are based on the names of initial letters. Thus, children who are taught that the made-up word TM is pronounced as "team" or that "beet" is spelled as BT can make some sense of these pairings. Children benefit from letter-name-based relationships at the beginnings of words even before they can read any real words with consistency and even before they can produce the names of many letters on their own (Experiment 1). Previous studies may have identified young children as logographic readers because children were not tested in situations in which alternative strategies, including those based on letter names, could have been observed.

Although young children do not necessarily adopt a logographic approach in their early attempts to read, they do seem to be prealphabetic readers in the sense of Ehri (1998). That is, they cannot yet take advantage of links between print and speech that are based on letter sounds when learning to read words. The terms logographic and prealphabetic are often used interchangeably, but our results suggest an important distinction. Children who cannot use relationships between print and speech at the level of single phonemes and who are, in this sense, prealphabetic can take advantage of other cues, such as letter names, when these cues are available and salient.

Further questions about stage theories of literacy development are raised by our finding that even adults take advantage of letter names when learning to read new words. This finding speaks against theories in which strategies characteristic of earlier stages are later replaced by different and more advanced strategies. Our results suggest that, in literacy development as in other aspects of cognitive development, the introduction of new strategies does not necessarily mean the abandonment of earlier strategies (e.g., Rittle-Johnson \& Siegler, 1999). As has also been argued by Perry and Ziegler (2000), an understanding of the mature reading system may require a consideration of its development.

Our results also shed light on the relationship between reading and spelling. The findings support the idea that children begin to use an alphabetic approach in spelling before they do so in reading. When learning to spell words, prereaders performed significantly worse in the visual condition (e.g., "wide" spelled as TM) than in the sound condition (e.g., "tame" spelled as TM; Experiment 3 ). In contrast, the lack of phoneme-grapheme relationships did not hinder prereaders' performance in the reading task, in which no significant difference between the visual and the sound conditions was observed (Experiment 1; Treiman \& Rodriguez, 1999). We also found that novice readers paid more attention to alphabetic relationships in the spelling task than in the reading task. Although the conclusions must remain tentative, resting as they do on comparisons across experiments, our findings support the view that reading and spelling develop out of step (Frith, 1985; Goswami \& Bryant, 1990). Spelling takes the lead early on, with progress toward the alphabetic principle occurring more rapidly in learning to spell than in learning to read.

Why might children be more able to use the alphabetic principle in spelling than in reading? The children in these experiments may have found it hard to remember the five meaningless two-letter responses of the spelling task without some principled way of generating each word's spelling from its pronunciation. The difficulty of the spelling task may prompt children to use more systematic methods of deriving the spellings from the sounds. Remembering the familiar monosyllabic words that are the responses in the reading task may not be as taxing. Children may thus use only the most obvious aids-those based on letter names-when connecting printed words to familiar spoken words. Our results do not support the idea, put forward by Seymour and Elder (1986), that differences between spelling and reading are a by-product of instruction. Since most of the children we tested were not receiving formal instruction in either reading or spelling, this is unlikely to be the case. The 
differences that we and others have observed between reading and spelling appear to reflect basic differences between the two tasks, as was also argued by Frith (1985) and Goswami and Bryant (1990).

Our findings suggest that exposing young children to words such as jail and eat may help them grasp the important idea that the spoken forms of words are related to their spellings. Because the names of some of the letters are heard in the spoken forms of these words, children may be able to appreciate that the words' spellings are systematically linked to their pronunciations. Of course, children must eventually learn that not all relationships between printed words and spoken words involve letter names. However, links that are based on letter names may give children an entry into the writing system. Our results further suggest that spelling should play an important role in literacy instruction for young children. Spelling may encourage children to use the alphabetic principle in a way that reading does not, and it may teach skills that eventually transfer to reading.

The word-learning task used here provides a promising way of investigating how children learn to connect print and speech. It allows researchers to focus on the learning process itself, rather than on the end result of that learning. Our results suggest that children grasp links based on letter names quite early and that such links continue to be important even for fluent readers. Links based on letter sounds are harder for children to appreciate and use. However, these connections appear to play a more important role in spelling than they do in reading.

\section{REFERENCES}

BARON, J. (1977). Mechanisms for pronouncing printed words: Use and acquisition. In D. LaBerge \& S. J. Samuels (Eds.), Basic processes in reading: Perception and comprehension (pp. 175-216). Hillsdale, NJ: Erlbaum.

Bradley, L., \& BRYANT, P. E. (1979). Independence of reading and spelling in backward and normal readers. Developmental Medicine \& Child Neurology, 21, 504-514.

BroоKs, L. R. (1977). Visual pattern in fluent word identification. In A. S. Reber \& D. L. Scarborough (Eds.), Toward a psychology of reading (pp. 143-181). Hillsdale, $\mathrm{NJ}$ : Erlbaum.

BYRNE, B. (1992). Studies in the acquisition procedure for reading: Rationale, hypotheses, and data. In P. B. Gough,L. C. Ehri, \& R. Treiman (Eds.), Reading acquisition (pp. 1-34). Hillsdale, NJ: Erlbaum.

De Abreu, M. D., \& Cardoso-Martins, C. (1998). Alphabetic access route in beginning reading acquisition in Portuguese: The role of lettername knowledge. Reading \& Writing: An Interdisciplinary Journal, 10, $85-104$

EHRI, L. C. (1998). Grapheme-phoneme knowledge is essential for learn- ing to read words in English. In L. C. Ehri \& J. L. Metsala (Eds.), Word recognition in beginning literacy (pp. 3-40). Mahwah, NJ: Erlbaum.

EHRI, L. C., \& Wilce, L. S. (1985). Movement into reading: Is the first stage of printed word learning visual or phonetic? Reading Research Quarterly, 20, 163-179.

FriTh, U. (1985). Beneath the surface of developmental dyslexia. In K. E. Patterson, J. C. Marshall, \& M. Coltheart (Eds.), Surface dyslexia: Neuropsychological and cognitive studies of phonological reading (pp. 301-330). Hove, U.K.: Erlbaum.

Goswami, U., \& BRyAnt, P. E. (1990). Phonological skills and learning to read. Hove, U.K.: Erlbaum.

Gough, P. B., \& Hillinger, M. L. (1980). Learning to read: An unnatural act. Bulletin of the Orton Society, 30, 179-196.

Huxford, L., Terrell, C., \& Bradley, L. (1991). The relationship between the phonological strategies employed in reading and spelling. Journal of Research in Reading, 14, 99-105.

Laing, E., \& Hulme, C. (1999). Phonological and semantic processes influence beginning readers' ability to learn to read words. Journal of Experimental Child Psychology, 73, 183-207.

Marsh, G., Friedman, M., Welch, V., \& Desberg, P. (1981). A cognitive-developmental theory of reading acquisition. In G. E. MacKinnon \& T. G. Waller (Eds.), Reading research: Advances in theory and practice (Vol. 3, pp. 199-221). San Diego: Academic Press.

O'Brien, R. G., \& KAISER, M. K. (1985). MANOVA method for analyzing repeated measures designs: An extensive primer. Psychological Bulletin, 97, 316-333.

Perry, C., \& Ziegler, J. C. (2000). Linguistic difficulties in language and reading development constrain skilled adult reading. Memory \& Cognition, 28, 739-745.

READ, C. (1975). Children's categorization of speech sounds in English (NCTE Research Report No.17). Urbana, IL: National Council of Teachers of English

Rittle-Johnson, B., \& Siegler, R. S. (1999). Learning to spell: Variability, choice, and change in children's strategy use. Child Development, 70, 332-348.

Seymour, P. H. K., \& Elder, L. (1986). Beginning reading without phonology. Cognitive Neuropsychology, 3, 1-36.

Snow, C. E., Burns, M. S., \& Griffin, P. (EDS.). (1998). Preventing reading difficulties in young children. Washington, DC: National Academy Press.

Treiman, R. (1993). Beginning to spell: A study of first-grade children. New York: Oxford University Press.

Treiman, R. (1994). Use of consonant letter names in beginning spelling. Developmental Psychology, 30, 567-580.

Treiman, R., \& CASSar, M. (1997). Can children and adults focus on sound as opposed to spelling in a phoneme counting task? Developmental Psychology, 33, 771-780.

Treiman, R., \& Rodriguez, K. (1999). Young children use letter names in learning to read words. Psychological Science, 10, 334-338.

Treiman, R., Tincoff, R., \& Richmond-Welty, E. D. (1996). Letter names help children to connect print and speech. Developmental Psychology, 32, 505-514.

Worden, P. E., \& BoetTCHER, W. (1990). Young children's acquisition of alphabet knowledge. Journal of Reading Behavior, 22, 277-295.

(Manuscript received October 6, 2000; revision accepted for publication June 7,2001 .) 